\title{
Rapid Regulation of Pain by Estrogens Synthesized in Spinal Dorsal Horn Neurons
}

\author{
Henry C. Evrard and Jacques Balthazart \\ Research Group in Behavioral Neuroendocrinology, Centre for Cellular and Molecular Neurobiology, University of Liège, B-4020 Liège, Belgium
}

In addition to exerting genomic actions via nuclear receptors within hours to days, estrogens also regulate neuronal activity much faster (within seconds) by activating neuronal membrane receptors coupled to intracellular second-messenger pathways. To date, the origin of estrogens inducing rapid effects in the brain remains unclear, although it is often ascribed to the gonads. We report here that an acute blockade of the endogenous synthesis of estrogens in the quail spinal dorsal horn markedly reduced, within 1 min, the behavioral responsiveness to a thermal painful stimulus. Similar rapid effects in the opposite direction were induced by estradiol. This finding identifies a new paracrine and nongenomic mechanism for the regulation of pain by estrogens. Such regulation was assumed previously to result only from slow genomic actions of estrogens arising from the ovaries. Also, quite importantly, this finding suggests that the numerous rapid nongenomic effects of estrogens in the CNS could depend on their immediate local production by the enzyme aromatase, independently from the gonads.

Key words: aromatase inhibitor; estrogens; rapid effects; nongenomic effects; membrane estrogen receptor; bird

\section{Introduction}

The hormone $17 \beta$-estradiol (E2) regulates a remarkably large spectrum of neural functions, including nociception (Amandusson et al., 1999; Bradshaw and Berkley, 2000; Liu and Gintzler, 2000; Evrard and Balthazart, 2003; Ji et al., 2003). The effects of E2 in neurons primarily rely on intracellular nuclear receptors [estrogen receptor $\alpha(\mathrm{ER} \alpha)$ and $\mathrm{ER} \beta$ ] controlling gene transcription and impacting physiology and behavior within hours to days (Jensen and DeSombre, 1973; Paech et al., 1996). In addition, E2 can interact with membrane binding sites [putative membrane estrogen receptors (mER)], altering second-messenger pathways, and thereby neuronal excitability, within seconds to minutes (Kelly et al., 1977; Pietras and Szego, 1977; Mermelstein et al., 1996; Joels, 1997). Recent in vitro studies (Toran-Allerand et al., 2002; Qiu et al., 2003) using application of exogenous estrogens partly unraveled the nature of mER and their appended signaling cascades. However, the origin of endogenous estrogens acting at the membrane level in vivo remains unclear. The enzyme aromatase catalyzes the formation of E2 from testosterone (T) in the gonads and also in other tissues, including the brain, in which aromatase has been found in perikarya and synapses (Naftolin et al., 1972, 1996). Aromatase activity (AA) was initially believed to be controlled only through slow changes in transcription of its gene CYP19 (Simpson et al., 1994). However, it was demonstrated recently that AA is also rapidly (within minutes) and reversibly inhibited by $\mathrm{Ca}^{2+}$-dependent phosphorylations in hypo-

Received April 29, 2004; revised June 23, 2004; accepted June 28, 2004.

This work was supported by National Institute of Mental Health Grant MH50388, Belgian Fonds de la Recherche Fondamentale Collective Grant 2.4555.01, and French Community of Belgium Grant ARC99/04-241.

Correspondence should be addressed to Henry C. Evrard, Department of Biology, Boston University, 5 Cummington Street, Boston, MA 02215. E-mail: hcevrard@bu.edu.

DOI:10.1523/JNEUROSCI.1638-04.2004

Copyright (C) 2004 Society for Neuroscience $\quad 0270-6474 / 04 / 247225-05 \$ 15.00 / 0$ thalamic neurons in male Japanese quail, a useful model for the study of neuronal aromatase (Balthazart and Ball, 1998; Balthazart et al., 2003). The expression of aromatase in various circumscribed brain areas and the rapid control of neuronal AA offer the possibility for rapid production of high concentrations of E2 within very discrete areas of the brain (perikaryal to synaptic levels) in which E2 could potentially bind mER.

During studies on the effects of E2 on nociception, we demonstrated the presence of aromatase in numerous nociceptive neurons all along the laminas I-III of the spinal cord in male and female quail (Blomqvist, 2000; Evrard et al., 2000, 2003). These laminas also express $\mathrm{ER} \alpha$ (as in mammals), and aromatization plays a crucial role for the slow genomic actions of T and E2 on nociception (Evrard and Balthazart, 2002b, 2003, 2004). The regulation of pain by estrogens is commonly assumed to result from genomic effects. Here, we propose that E2 can also rapidly regulate the spinal mechanisms of nociception and that such regulation depends on rapid control of spinal aromatase. We injected the specific nonsteroidal aromatase inhibitor vorozole in the quail spinal cord to mimic fast-inhibiting phosphorylations of aromatase, and we observed that an acute inhibition of the endogenous spinal estrogen synthesis reduced, within $1 \mathrm{~min}$, a behavioral response typically triggered by painful stimuli in birds (as in mammals). This finding provides evidence for the existence of rapid estrogenic regulation of nociception. Furthermore, it demonstrates that rapid effects of E2 in neurons may depend on the rapid regulation of local AA, perhaps independently from the gonads.

\section{Materials and Methods}

Subjects. Adult male Japanese quail (Coturnix japonica; $n=60$ ) were reared under a long day photoperiod (16/8 hr light/dark cycle), leading to a full development of testicles and to a high plasma concentration of $\mathrm{T}$ 
( $\pm 2 \mathrm{ng} / \mathrm{ml}$ plasma) (Balthazart et al., 1987). All experiments were approved by the Ethics Committee of the University of Liège and complied with the International Association for the Study of Pain guidelines for the use of conscious animals in pain research.

Hot water test. One foot of the subject was immersed in a $54^{\circ} \mathrm{C}$ hot water bath. We recorded the latency before the subject withdrew its foot from water in a rapid reflex-like motion as described previously (Le Bars et al., 2001; Evrard and Balthazart, 2002a). The cutoff time was $20 \mathrm{sec}$. All data were analyzed by repeated measures ANOVA with Tukey's honestly significant difference post hoc test when necessary. The experimenter was blind to the animals' chronic and acute hormonal treatments (see below).

Chronic hormonal treatments. Twenty-two males were castrated (CX) under deep anesthesia at the age of 4 weeks, and, 2 weeks later, they were subcutaneously implanted with SILASTIC capsules (Degania Silicone, Cumberland, RI) that were empty $(n=6$; CX), filled with crystalline T ( $n=8$; CX plus T; Sigma-Aldrich, St. Louis, MO), or filled with crystalline E2 ( $n=8$; CX plus E2; Sigma-Aldrich), by procedures that have been described previously (Evrard and Balthazart, 2004). Experiments with these birds started 2 weeks after implantation of the capsules.

Experiments with CX, CX plus T, and CX plus E2 birds. In a first experiment, half of the subjects in each group were injected intraperitoneally with the nonsteroidal aromatase inhibitor vorozole $(4.8 \mathrm{mg} / \mathrm{kg}$ body weight; Janssen Pharmaceutica, Beerse, Belgium) (Wouters et al., 1993). The other half received the vehicle solution (mix of polyethylene glycol and $0.9 \%$ saline, $3 / 1 \mathrm{v} / \mathrm{v}$; also used for all steroids injected in this study). The foot-withdrawal latency was recorded in all subjects $20 \mathrm{~min}$ after injection. One week later, the test was repeated, but the treatment was reversed for each bird. In a second experiment, the same subjects (CX, CX plus T, and CX plus E2) were used to test with the same protocol the rapid effect of intraperitoneal E2 (4.4 mg of E2 per kilogram of body weight) or its vehicle.

Intrathecal cannulation. Gonadally intact male quail $(n=28)$ were deeply anesthetized with a mix of ketamine, xylazine, and $0.9 \%$ saline. The lumbar area of the back was plucked and painted with a local anesthetic. The skin was incised along the lumbar spine on a length of $2 \mathrm{~cm}$. At this level, vertebrae (thoracic 5 to sacral 2) are fused to form the synsacrum. A hole (diameter, $1 \mathrm{~mm}$ ) was drilled in the rostrodorsal part of the synsacrum, and the subjacent membrane was delicately incised. A permanent indwelling cannula (inner diameter, $0.28 \mathrm{~mm}$; outer diameter, $0.61 \mathrm{~mm}$; total length, $3 \mathrm{~cm}$; filled with vehicle; Becton Dickinson, Mountain View, CA) was inserted into the subarachnoid space caudally through the drilled hole for $8 \mathrm{~mm}$ [i.e., until it reached the spinal segments innervating the foot (lumbar 2-6)]. The cannula was secured with dental cement, the skin was sutured, and the subject was returned to its home cage after complete awakening. Its recovery was monitored daily for 1 week before starting experiments. Seven birds displaying locomotor deficits were removed from the experiment. In the other birds $(n=21)$, the foot-withdrawal latency measured before and 1 week after surgery at $54^{\circ} \mathrm{C}$ was not significantly changed (before, $2.56 \pm 0.5 \mathrm{sec}$; after, $2.47 \pm$ $0.4 \mathrm{sec})$. At the end of the experiment, subjects were killed, and the position of the cannula was verified by a careful dissection. In all cases in which no locomotor dysfunction was noticed $(n=21)$, the cannula was positioned along the midline without lesion of the spinal cord.

Intracerebroventricular cannulation. Ten gonadally intact male quail were deeply anesthetized with a mix of ketamine, xylazine, and $0.9 \%$ saline and placed in a stereotaxic apparatus with a pigeon head holder. A permanent cannula was inserted under stereotaxic control in the third ventricle as described previously (Castagna et al., 1998).

Experiments with intrathecally and intracerebroventricularly cannulated subjects. All intrathecal injections had a volume of $5 \mu \mathrm{l}$ of solution that was injected into the lumbar subarachnoid space. Each injection was followed by a $7 \mu \mathrm{l}$ vehicle flush. In a first experiment, all birds received an intrathecal injection of vorozole ( $15 \mu \mathrm{g}$ per $5 \mu \mathrm{l}$; half of the subjects) or of its vehicle solution $(5 \mu \mathrm{l})$. The responsiveness to hot water was measured before and 1, 5, and $30 \mathrm{~min}$ after injection. One week later, the same test was repeated, but treatments were reversed in each subject. In the second and third experiments, the same procedure was used to test the effect of 1,4,6-androstatriene-3,17-dione (ATD) ( $15 \mu \mathrm{g} / 5 \mu \mathrm{l}$; same vehicle) and
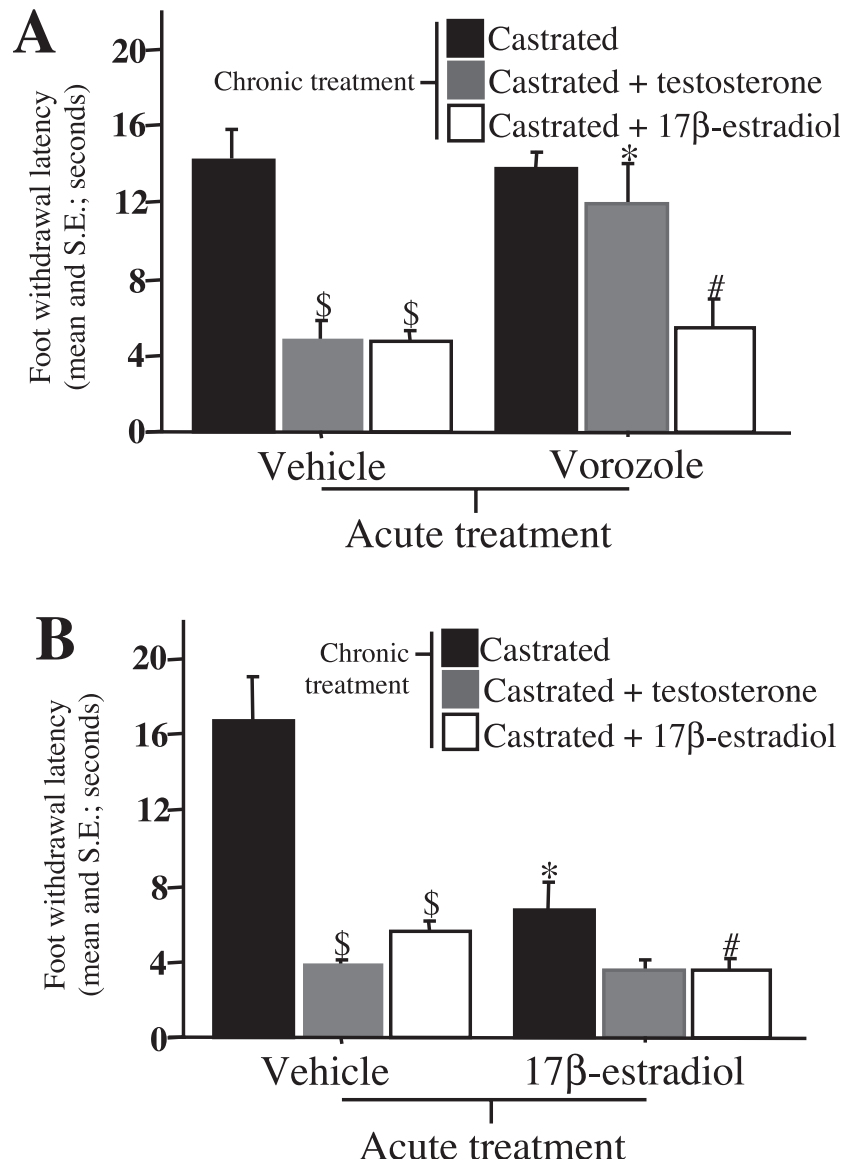

Figure 1. Peripheral treatment with an aromatase inhibitor or with $\mathrm{E} 2$ rapidly increases or decreases, respectively, withdrawal latency from a $54^{\circ} \mathrm{C}$ water bath. $A$, Foot-withdrawal latency in the hot water test in castrated subjects with empty, T-filled, or E2-filled subcutaneous implants 20 min after an intraperitoneal injection of vorozole or its vehicle. $B$, Foot-withdrawal latency in the same subjects $20 \mathrm{~min}$ after an intraperitoneal injection of E2 or its vehicle. Tukey's tests; ${ }^{\$} p<0.01$ and ${ }^{\#} p<0.05$ versus castrates submitted to the same acute treatment; ${ }^{*} p<$ 0.01 versus vehicle-injected birds submitted to the same chronic treatment.

E2 $(4 \mu \mathrm{g} / 5 \mu \mathrm{l}$; same vehicle), respectively, instead of vorozole. Finally, this protocol was used again in a fourth experiment in which half of the subjects received an injection of vorozole, whereas the other half received an injection of vorozole $(15 \mu \mathrm{g} / 5 \mu \mathrm{l})$ mixed with E2 $(4 \mu \mathrm{g} / 5 \mu \mathrm{l})$.

In addition, 10 gonadally intact males with intracerebroventricular cannulas were injected into the third ventricle with either vorozole (30 $\mu \mathrm{g} / 1 \mu \mathrm{l} ; n=5)$ or its vehicle $(n=5)$. Their foot-withdrawal latency from $54^{\circ} \mathrm{C}$ water was measured as above.

\section{Results}

Experiments with CX, CX plus T, and CX plus E2 birds

As expected from our previous work (Evrard and Balthazart, 2004), chronic treatments with T or E2 in castrates decreased the foot-withdrawal latency compared with castrates with empty implants (Fig. 1 $A, B$ ). However, 20 min after an intraperitoneal injection of vorozole, the latency was markedly increased in CX plus T but not in CX plus E2 or CX subjects (chronic treatment, $F_{(2,14)}=18.338, p=0.0001$; acute treatment, $F_{(1,14)}=8.753, p=$ 0.0104 ; interaction, $F_{(2,14)}=6.662, p=0.0093$; results of the Tukey's post hoc tests are shown in figures) (Fig. $1 A$ ). Conversely, 20 min after its injection, E2 significantly reduced the withdrawal latency (chronic treatment, $F_{(2,15)}=25.749, p=0.0001$; acute treatment, $F_{(1,15)}=30.491, p=0.0001$; interaction, $F_{(2,15)}=$ $18.459, p=0.0001$ ) (Fig. $1 B$ ) in CX males displaying, in control conditions, a latency significantly higher than in gonadally intact 

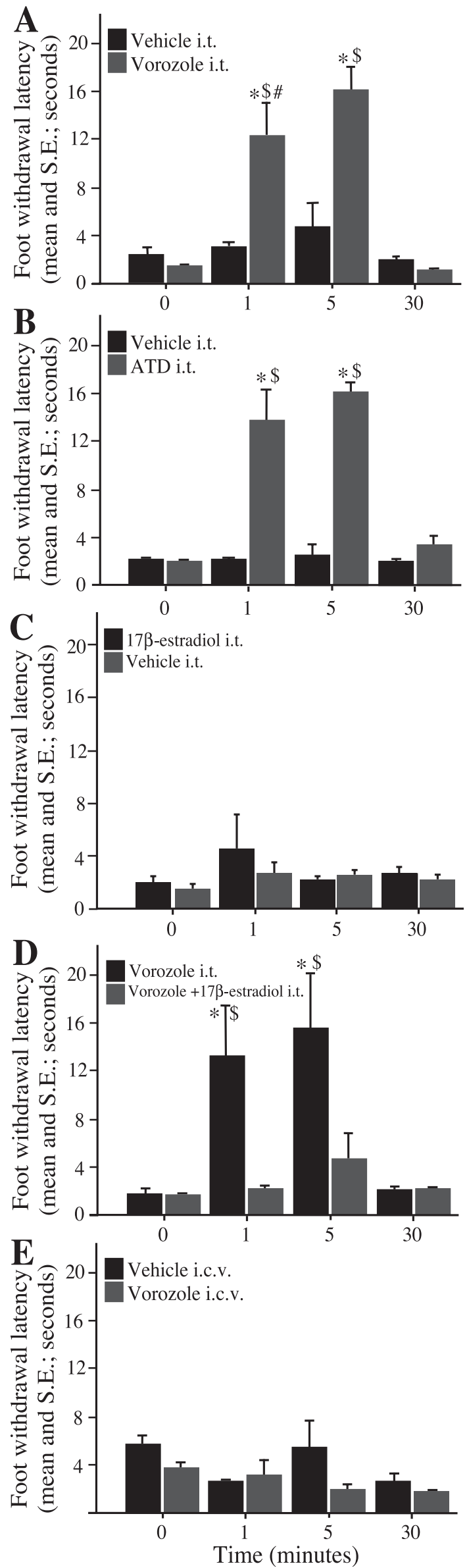

or steroid-implanted birds (Evrard and Balthazart, 2004). In CX plus T or CX plus E2 birds, the latency was not further decreased by the acute E2 injection, presumably because the estrogensensitive mechanisms underlying the change in responsiveness were already saturated in these birds or the latency had reached the lowest possible value.

\section{Experiments with intrathecal and intracerebroventricular cannulated birds}

To test whether the effect of systemic vorozole on pain response resulted from an inhibition of the spinal aromatase, vorozole was directly injected into the lumbar subarachnoid space in gonadally intact males with high endogenous levels of plasma $\mathrm{T}$. Compared with vehicle-treated birds, the latencies in vorozole-treated birds increased significantly 1 and $5 \mathrm{~min}$ after injection (time effect, $F_{(3,21)}=19.362, p<0.0001$; intrathecal injection effect, $F_{(1,7)}=$ $22.709, p=0.0020$; interaction, $F_{(3,21)}=10.700, p=0.0002$ ) (Fig. $2 A)$. This effect vanished after $30 \mathrm{~min}$. Furthermore, with the same protocol, ATD, another very specific aromatase inhibitor structurally unrelated to vorozole, induced similar effects on the latency (time effect, $F_{(3,21)}=18.008, p<0.0001$; intrathecal injection effect, $F_{(1,7)}=12.782, p=0.0090$; interaction, $F_{(3,21)}=$ $6.329, p=0.0032$ ) (Fig. 2B). As expected from the experiment using intraperitoneal injections, E2 alone had no effect on the latency (time effect, $F_{(3,21)}=1.103, p=0.3736$; intrathecal injection effect, $F_{(1,7)}=0.392, p=0.5545$; interaction, $F_{(3,21)}=0.795$, $p=0.5126)$ (Fig. 2C). However, to further test the neurochemical specificity of the effect of vorozole, we also coinjected E2 and vorozole into the spinal cord and measured latency as before. Vorozole injected alone induced the aforementioned increase in latency. However, when simultaneously injected, vorozole and E2 failed to alter latencies, indicating that the behavioral effects of the aromatase inhibitors were effectively caused by the local depletion of the E2 concentration (time effect, $F_{(3,24)}=9.952, p=$ 0.0002; intrathecal injection effect, $F_{(1,8)}=7.430, p=0.0260$; interaction, $F_{(3,24)}=5.833, p=0.0038$ ) (Fig. $2 D$ ). In contrast with intrathecal injections, intracerebroventricular injections of vorozole into the third ventricle did not affect the foot-withdrawal latency from hot water, suggesting that vorozole exerted its effects locally in the spinal cord and not through diffusion to the brain after an intrathecal injection (time effect, $F_{(3,21)}=0.392, p=0.1188$; vorozole effect, $F_{(1,7)}=3.058, p=0.1238$; interaction, $F_{(3,21)}=$ $1.178, p=0.3419)$ (Fig. 2E).

\section{Discussion}

\section{Rapid effects of spinally synthesized estrogens on pain}

For several years, evidence has accumulated indicating that $\mathrm{T}$ and E2 regulate nociception in males and females in humans (Dao and LeResche, 2000; Fillingim, 2000), monkeys (Negus and Mello, 1999), rodents (Amandusson et al., 1999; Nayebi and Ahmadiani, 1999; Liu and Gintzler, 2000; Khasar et al., 2003), and birds (Evrard and Balthazart, 2003, 2004; Hau et al., 2004). To date, only genomic

Figure 2. Spinal aromatase inhibition results in a rapid increase of foot-withdrawal latency from a $54^{\circ} \mathrm{C}$ water bath; this effect is bypassed by E2. $A-C$, Latency in gonadally intact subjects before and 1,5, and 30 min after an intrathecal (i.t.) injection of vorozole $(A)$, ATD ( $B)$, or E2 ( $C$ ) or after injection of the corresponding vehicle. $D$, Latency in gonadally intact subjects before and 1,5 , and 30 min after an intrathecal injection of vorozole alone or mixed with E2. E, Latency in gonadally intact subjects before and 1,5, and $30 \mathrm{~min}$ after an intracerebroventricular (i.c.v.) injection of vorozole or its vehicle. Tukey's tests; ${ }^{*} p<0.01$ versus 0 and 30 min after the same treatment; ${ }^{\zeta} p<0.01$ versus other condition after the same amount of time; $\#<<0.05$ versus 5 min after the same treatment. 
actions of estrogens have been reported for the regulation of pain behaviors. The present study shows that E2 can also rapidly modulate behavioral responsiveness to a painful stimulus at the spinal level; importantly, it also demonstrates that this rapid effect depends on rapid control of local aromatization of androgens into estrogens directly in the spinal cord.

This study suggests that the effect of T on nociception in males (Khasar et al., 2003; Hau et al., 2004) requires, at least in part, aromatization into E2, and this aromatization could control T-dependent pains in men (e.g., cluster headache) (Klimek, 1985). The vernal increase in plasma $T$ concentration and brain aromatization activates male reproductive behaviors. In addition, the seasonal rise in plasma $\mathrm{T}$ in males could have a profound effect on nociceptive thresholds and thereby indirectly play a role in the success of reproduction. For instance, it has been proposed recently that a function of $\mathrm{T}$ during male aggressive encounters would be to increase and/or decrease nociception, which could modulate the willingness to engage in and sustain high-intensity fights (Evrard and Balthazart, 2003; Hau et al., 2004).

Aromatase is also expressed in the female spinal cord at the same level as in males, without sex difference in the number or distribution of aromatase-immunoreactive cells between sexes and aromatase activity (Evrard et al., 2000, 2001). Spinal E2 could therefore play a role in the estrogenic regulation of nociception in females, including aging females with lower gonadal estrogen production. During reproduction, the estrogenic regulation of pain in females potentiates the spinally mediated analgesia during sexual intercourse and pregnancy (Komisaruk and Whipple, 2000; Gintzler and Liu, 2001). On the other hand, from a clinical perspective, its dysfunction could result in severe pain conditions, including dyspareunia, migraine, fibromyalgia, and irritable bowel syndrome (Fillingim, 2000). Whether spinal aromatase and rapid E2 effects regulate the sensory system during reproduction and in steroid-dependent pain conditions is currently under investigation.

\section{Possible targets for the rapid effects of estrogens in the spinal cord}

In the rat hippocampus, E2 rapidly potentiated glutamate (kainate)-induced currents through a second-messenger cascade (Gu et al., 1999). In guinea pig hypothalamic neurons, the activation by $\mathrm{E} 2$ of a unique $\mathrm{G}_{\mathrm{q}}$-protein-coupled mER reduced, within minutes, the potency of $\mathrm{GABA}_{\mathrm{B}}$ and opioid receptor agonists to activate $\mathrm{G}$-protein coupled to inwardly rectifying $\mathrm{K}^{+}$ channels (GIRKs) (Kelly et al., 1992; Qiu et al., 2003). Interestingly, in the spinal dorsal horn, both kainate-induced currents and activation of GIRKs by GABA or opioids play a crucial role in the activation of the central pain pathways and in analgesia, respectively (Li et al., 1999; Blednov et al., 2003; Mitrovic et al., 2003). Therefore, the marked decrease in skin sensitivity induced immediately after an inhibition of spinal aromatase and its counterbalancing by E2 point to new mechanisms through which spinal kainate receptor-mediated pain and GIRK-dependent analgesia could be rapidly regulated [for additional discussion on the endogenous inhibition of spinal AA see, Evrard et al. (2003)].

\section{Expression of aromatase in the spinal cord of other species}

The phylogenic divergence of avian and mammalian species occurred hundreds of millions of years ago (Benton and Ayala, 2003). Nevertheless, despite expected differences (Jordt and Julius, 2002), the similar organization and function of the spinal dorsal horn in both classes suggests a good conservation of the basic spinal mechanisms of nociception (Butler and Hodos, 1996;
Necker, 2000). Moreover, the effects of E2 on nociception and the presence of ER $\alpha$ in the spinal laminas I-III in birds and rodents also hint at a well conserved steroid-dependent regulation of nociception (Evrard and Balthazart, 2002b, 2004). Whether this apparent conservation includes spinal aromatization and nongenomic effects of spinally synthesized E2 is currently under investigation. We already demonstrated the presence of aromataseimmunoreactive structures in the spinal dorsal horn in snakes and rodents (rats and mice, laminas I-II, V, and X, and the lateral spinal nucleus) (Evrard et al., 2001; Huynh and Krohmer, 2002) (H. C. Evrard, J. Balthazart, and M. S. Erskine, unpublished observations), and we are now assessing in rodents whether this immunoreactive aromatase represents physiologically active enzyme capable of rapidly altering nociception.

\section{Effects of locally produced estrogens at the organismic level and on other brain and bodily functions}

Previous studies described the rapid effects of exogenous E2 on the excitability of neurons in vitro, whereas the present work reports the effects of endogenous estrogens on a behavioral endpoint and thereby indicates that, to date, observations made at the cellular level are also true at the organismic level. Rapid effects of estrogens occur in multiple areas of the nervous system [e.g., hypothalamus (Qiu et al., 2003), hippocampus (Gu et al., 1999), and neostriatum (Mermelstein et al., 1996)], in various peripheral tissues [e.g., adipocytes (Dos Santos et al., 2002) and gametes (Morley et al., 1992; Luconi et al., 2001)], and in tumors (Aronica et al., 1994; Huang and Jan, 2001). Previously, studies of these effects were based on the application of exogenous E2 and did not provide information regarding the origin of estrogens that induce rapid effects in vivo. Although this origin is often attributed to the gonads, various studies have reported that circulating concentrations of E2 were insufficient to trigger rapid effects in neurons (Kelly and Ronnekleiv, 2002). Moreover, the ubiquitous and passive diffusion of gonadal estrogens in the body does not readily provide a mechanism through which $\mathrm{E} 2$ concentration could be acutely raised within a discrete area and at a precise moment. In contrast, the fast regulation of local aromatization could finely tune local E2 bioavailability and thereby efficiently control the kinetics of E2 membrane actions. The present results demonstrate that the expression of aromatase in the vicinity of cells sensitive to rapid estrogen effects can occur and that the rapid effects of E2 may depend on local aromatization.

\section{References}

Amandusson A, Hallbeck M, Hallbeck A-L, Hermanson O, Blomqvist A (1999) Estrogen-induced alterations of spinal cord enkephalin gene expression. Pain 83:243-248.

Aronica SM, Lee Kraus W, Katzenellenbogen BS (1994) Estrogen action via the cAMP signaling pathway: stimulation of adenylate cyclase and cAMPregulated gene transcription. Proc Natl Acad Sci USA 91:8517-8521.

Balthazart J, Ball GF (1998) New insights into the regulation and function of brain estrogen synthase (aromatase). Trends Neurosci 21:243-249.

Balthazart J, Delville Y, Sulon Y, Hendrick JC (1987) Plasma levels of luteinizing hormone and of five steroids in photostimulated, castrated and testosterone-treated male and female Japanese quail (Coturnix coturnix japonica). Gen Comp Endocrinol 5:31-36.

Balthazart J, Baillien M, Charlier TD, Ball GF (2003) Calcium-dependent phosphorylation processes control brain aromatase in quail. Eur J Neurosci 17:1591-1606.

Benton MJ, Ayala FJ (2003) Dating the tree of life. Science 300:1698-1700.

Blednov YA, Stoffel M, Alva H, Harris RA (2003) A pervasive mechanism for analgesia: activation of GIRK2 channels. Proc Natl Acad Sci USA 100:277-282.

Blomqvist A (2000) Sex hormones and pain: a new role for brain aromatase? J Comp Neurol 423:549-551. 
Bradshaw HB, Berkley KJ (2000) Estrous changes in responses of rat gracile nucleus neurons to stimulation of skin and pelvic viscera. J Neurosci 20:7722-7727.

Butler AN, Hodos W (1996) Comparative vertebrate neuroanatomy, evolution and adaptation. New York: Wiley.

Castagna C, Absil P, Foidart A, Balthazart J (1998) Systemic and intracerebroventricular injections of vasotocin inhibit appetitive and consummatory components of male sexual behavior in Japanese quail. Behav Neurosci 112:233-250.

Dao TT, LeResche L (2000) Gender differences in pain. J Orofac Pain 14:169-184.

Dos Santos EG, Dieudonne MN, Pecquery R, Le Moal V, Giudicelli Y, Lacasa D (2002) Rapid nongenomic E2 effects on p42/p44 MAPK, activator protein-1, and cAMP response element binding protein in rat white adipocytes. Endocrinology 143:930-940.

Evrard HC, Balthazart J (2002a) The assessment of nociceptive and nonnociceptive skin sensitivity in the Japanese quail (Coturnix japonica). J Neurosci Methods 116:135-146.

Evrard HC, Balthazart J (2002b) Localization of oestrogen receptors in the sensory and motor areas of the spinal cord in Japanese quail (Coturnix japonica). J Neuroendocrinol 14:894-903.

Evrard HC, Balthazart J (2003) Presence of aromatase in the dorsal horns of the spinal cord: functional implications. Ann NY Acad Sci 1007:263-271.

Evrard HC, Balthazart J (2004) Aromatization of androgens into estrogens reduces response latency to an aversive thermal stimulus in male quail. Horm Behav 45:181-189.

Evrard H, Baillien M, Foidart A, Absil P, Harada N, Balthazart J (2000) Localization and controls of aromatase in the quail spinal cord. J Comp Neurol 423:552-564.

Evrard HC, Harada N, Balthazart J (2001) Localization of estrogen-synthase (aromatase) in the rat spinal cord. Soc Neurosci Abstr 27:508.6.

Evrard HC, Willems E, Harada N, Balthazart J (2003) Specific innervation of aromatase neurons by substance $\mathrm{P}$ fibers in the dorsal horn of the spinal cord in quail. J Comp Neurol 465:309-318.

Fillingim RB, ed (2000) Sex, gender, and pain. Seattle: IASP.

Gintzler AR, Liu N-J (2001) The maternal spinal cord: biochemical and physiological correlates of steroid-activated antinociceptive processes. Prog Brain Res 133:83-97.

Gu Q, Korach KS, Moss RL (1999) Rapid action of 17beta-estradiol on kainate-induced currents in hippocampal neurons lacking intracellular estrogen receptors. Endocrinology 140:660-666.

Hau M, Dominguez OA, Evrard HC (2004) Testosterone reduces responsiveness to nociceptive stimuli in a wild bird. Horm Behav 46:165-170.

Huang JK, Jan CR (2001) Mechanism of estrogens-induced increases in intracellular $\mathrm{Ca}^{2+}$ in PC3 human prostate cancer cells. Prostate 47:141-148.

Huynh KH, Krohmer RW (2002) Seasonal variation of aromatase immunoreactivity in the spinal cord of the male red-sided garter snake. Soc Behav Neuroendocrinol Abstr 105.

Jensen EV, DeSombre ER (1973) Estrogen-receptor interaction. Science 182:126-134.

Ji Y, Murphy AZ, Traub RJ (2003) Estrogen modulates the visceromotor reflex and responses of spinal dorsal horn neurons to colorectal stimulation in the rat. J Neurosci 23:3908-3915.

Joels M (1997) Steroid hormones and excitability in the mammalian brain. Front Neuroendocrinol 18:2-48.

Jordt SE, Julius D (2002) Molecular basis for species-specific sensitivity to "hot" chili peppers. Cell 108:421-430.

Kelly MJ, Ronnekleiv OK (2002) Rapid membrane effects of estrogen in the central nervous system. In: Hormones, brain and behavior (Pfaff DW, ed), pp 361-380. New York: Elsevier Science.

Kelly MJ, Moss RL, Dudley CA (1977) The effects of microelectrophoretically applied estrogen, cortisol and acetylcholine on medial preopticseptal unit activity throughout the estrous cycle of the female rat. Exp Brain Res 30:53-64.

Kelly MJ, Loose MD, Ronnekleiv OK (1992) Estrogen suppresses $\mu$-opioidand $\mathrm{GABA}_{\mathrm{B}}$-mediated hyperpolarization of hypothalamic arcuate neurons. J Neurosci 12:2745-2750.
Khasar SG, Green PG, Gear RW, Isenberg W, Levine JD (2003) Gonadal hormones do not account for sexual dimorphism in vagal modulation of nociception in the rat. J Pain 4:190-196.

Klimek A (1985) Use of testosterone in the treatment of cluster headache. Eur Neurol 24:53-56.

Komisaruk BR, Whipple B (2000) How does vaginal stimulation produce pleasure, pain, and analgesia? In: Sex, gender, and pain (Fillingim RB, ed), pp 109-134. Seattle: IASP.

Le Bars D, Gozariu M, Cadden SW (2001) Animal models of nociception. Pharmacol Rev 53:597-652.

Li P, Wilding TJ, Kim SJ, Calejesan AA, Huettner JE, Zhuo M (1999) Kainate-receptor-mediated sensory synaptic transmission in mammalian spinal cord. Nature 397:161-164.

Liu NJ, Gintzler AR (2000) Prolonged ovarian sex steroid treatment of male rats produces antinociception: identification of sex-based divergent analgesic mechanisms. Pain 85:273-281.

Luconi M, Bonaccorsi L, Forti G, Baldi E (2001) Effects of estrogenic compounds on human spermatozoa: evidence for interaction with a nongenomic receptor for estrogen on human sperm membrane. Mol Cell Endocrinol 178:39-45.

Mermelstein PG, Becker JB, Surmeier DJ (1996) Estradiol reduces calcium currents in rat neostriatal neurons via a membrane receptor. J Neurosci 16:595-604.

Mitrovic I, Margeta-Mitrovic M, Bader S, Stoffel M, Jan LY, Basbaum AI (2003) Contribution of GIRK2-mediated postsynaptic signaling to opiate and alpha 2-adrenergic analgesia and analgesic sex differences. Proc Natl Acad Sci USA 100:271-276.

Morley P, Whitfield JF, Vanderhyden BC, Tsang BK, Schwartz JL (1992) A new, nongenomic estrogen action: the rapid release of intracellular calcium. Endocrinology 131:1305-1312.

Naftolin F, Ryan KJ, Petro Z (1972) Aromatization of androstenedione by the anterior hypothalamus of adult male and female rats. Endocrinology 90:295-298.

Naftolin F, Horvath TL, Jakab RL, Leranth C, Harada N, Balthazart J (1996) Aromatase immunoreactivity in axon terminals of the vertebrate brain. An immunocytochemical study on quail, rat, monkey and human tissues. Neuroendocrinology 63:149-155.

Nayebi AR, Ahmadiani A (1999) Involvement of the spinal serotonergic system in analgesia produced by castration. Pharmacol Biochem Behav 64:467-471.

Necker R (2000) Functional organization of the spinal cord. In: Sturkie's avian physiology (Whittow GC, ed), pp 71-81. San Diego: Academic.

Negus SS, Mello NK (1999) Opiod antinociception in ovariectomized monkeys: comparison with antinociception in males and effects of estradiol replacement. J Pharmacol Exp Ther 290:1132-1140.

Paech K, Webb P, Kuiper GG, Nilsson S, Gustafsson J, Kushner PJ, Scanlan TS (1996) Differential ligand activation of estrogen receptors $\operatorname{ER} \alpha$ and $\operatorname{ER} \beta$ at AP1 sites. Science 277:1508-1510.

Pietras RJ, Szego CM (1977) Specific binding sites for estrogen at the outer surfaces of isolated endometrial cells. Nature 265:69-70.

Qiu J, Bosch MA, Tobias SC, Grandy DK, Scanlan TS, Ronnekleiv OK, Kelly MJ (2003) Rapid signaling of estrogen in hypothalamic neurons involves a novel G-protein-coupled estrogen receptor that activates protein kinase C. J Neurosci 23:9529-9540.

Simpson ER, Mahendroo MS, Means GD, Kilgore MW, Hinshelwood MM, Graham-Lorence S, Amarneh B, Ito Y, Fisher CR, Michael MD, Mendelson CR, Bulun SE (1994) Aromatase cytochrome P450, the enzyme responsible for estrogen biosynthesis. Endocr Rev 15:342-355.

Toran-Allerand CD, Guan X, MacLusky NJ, Horvath TL, Diano S, Singh M, Connolly Jr ES, Nethrapalli IS, Tinnikov AA (2002) ER-X: a novel, plasma membrane-associated, putative estrogen receptor that is regulated during development and after ischemic brain injury. J Neurosci 22:8391-8401.

Wouters W, Van Ginckel R, Krekels M, Bowden C, De Coster R (1993) Pharmacology of vorozole. J Steroid Biochem Mol Biol 44:617-621. 